\title{
FETICHE E MERCADORIA: REFLEXÃO DE WALTER BENJAMIN SOBRE GRANDVILLE OU AS EXPOSIÇÕES UNIVERSAIS
}

\author{
Ítalo Andrade Lima'
}

\begin{abstract}
RESUMO
A reflexão sobre os apontamentos de Benjamin acerca de Grandville ou as exposições universais, presentes no exposé de 1935 - intitulado Paris a capital do século XIX - incide sobre o fetichismo, a mercadoria e o caráter fantasmagórico da cultura capitalista, quando é ressaltado aquilo que Benjamin denomina de verdadeiro local de peregrinação ao fetiche da mercadoria, e onde são investigados os fenômenos decorrentes da mercadoria, como nova candidata à mediadora das relações sociais. Essa interferência contribui de forma decisiva quer no plano ideológico quer na constituição da vida e do espaço social.
\end{abstract}

Palavras-chaves: Fetichismo. Mercadoria. Exposições Universais. Capitalismo. Cultura.

\section{FETISH AND MERCHANDISE: REFLECTION ON WALTER BENJAMIN GRANDVILLE OR UNIVERSAL EXHIBITIONS}

\begin{abstract}
Reflection of Benjamin notes about Grandville or universal, present exhibitions exposé in 1935 - entitled Paris the capital of the nineteenth century - focuses on fetishism, merchandise and the ghostly character of capitalist culture, when it is pointed out what Benjamin calls the true place of pilgrimage to the commodity fetish, and where are investigated phenomena arising from the merchandise as new candidate mediator of social relations. This interference contributes decisively either ideologically or in the constitution of social life and space.
\end{abstract}

Keywords: Fetishism. Merchandise. Universal Exhibitions. Capitalism. Culture.

\footnotetext{
1 Ítalo Andrade Lima é Mestrando em Filosofia pela Universidade Estadual do Ceara (CMAF/UECE). Bolsista CNPQ. Italoandrad27@hotmail.com.
} 
Nossa reflexão sobre o fetiche e a mercadoria no exposé de 1935, intitulado Paris a capital do século XIX, centrar-se-á nas notas de Benjamin sobre Grandville ou as exposições universais. Nossa opção em refletir sobre tal escrito justifica-se por um duplo aspecto: primeiro, por compreender que tal exposé, assim como aquele de 1939, que leva o mesmo título, representa o esboço de um projeto ainda maior, como descrito por nosso autor, "meu trabalho entrou num novo estágio, aliás, o primeiro que vagamente se aproxima de um livro"2; e segundo por entender que tal escrito nos permite uma compreensão do movimento de modernização parisiense no século XIX, bem como os impactos desta modernização na vida social. Assim, antes de tudo, esse escrito nos remonta à extrema vinculação entre o avanço do projeto moderno de desenvolvimento e os efeitos deste na vida social, uma articulação intensa entre conteúdo e forma, que Walter Benjamin passa a investigar.

Desse modo, a Paris do século XIX torna-se objeto da reflexão de Benjamin, visto que nesse período o processo de modernização ${ }^{3}$, com o desenvolvimento das forças produtivas, passa a tornar cada vez mais latente as contradições inerentes à forma capitalista de produção. Os impactos desta modernização na transformação do espaço da cidade, na vida cotidiana e na constituição do fazer social são características centrais abordadas por Benjamin no escrito aqui tratado.

A crítica benjaminiana não se reporta, exclusivamente, ao âmbito da economia política. Benjamin pretende, antes de qualquer coisa, investigar os fenômenos decorrentes do avanço do capitalismo, para isso é fundamental a reflexão sobre a cultura e as transformações desta. Daí a consideração de Benjamin localizar-se na relação entre o novo ethos, aquele determinado em geral pela forma capitalista de produção, e o pelo fazer social, determinado em geral, pelos

2 BENJAMIN, W.; SCHOLEM, G. Correspondências. Trad. Neusa Soliz. São Paulo: Perspectiva, 1993, p. 218.

${ }^{3}$ De acordo com Lowy: É sobretudo no Livro das passagens parisienses e nos diferentes textos dos anos 1936-40 que Benjamin vai desenvolver sua visão da história, dissociando-se, de modo mais ou menos radical, das "ilusões de progresso" hegemônicas no seio do pensamento de esquerda alemã e europeia. Em um artigo publicado em 1937 na célebre Zeitschrift für Sozialforschung, a revista da Escola de Frankfurt (já exilada nos Estados Unidos), dedicado ao historiador e colecionador Eduard Fuchs, ele ataca o marxismo social democrata, mistura de positivismo, evolucionismo darwinista e culto do progresso: "Ele não podia ver na evolução da técnica outra coisa a não ser o progresso das ciências sociais naturais e não a regressão social [...] As energias que a técnica desenvolve para além desse limite são destrutivas. Colocam em primeira linha a técnica da guerra e sua preparação pela imprensa". LOWY, M. A filosofia da história em Walter Benjamin, disponível em http://www.scielo.br/scielo.php?pid=S010340142002000200023\&script=sci_artext. 
espetáculos das exposições universais, pelo caráter fantasmagórico da cultura capitalista e pela mercadoria enquanto centro dos desejos.

Assim, ao tratar dos impactos do processo de modernização sobre o fazer social, do avanço da tecnificação e as consequências desses elementos em relação à esfera da vida humana, Benjamin argumenta sobre o fetichismo, a mercadoria e o caráter fantasmagórico da cultura capitalista. Daí Benjamin principiar seu escrito Grandville ou as exposições universais com a seguinte afirmação: "As exposições universais são lugares de peregrinação ao fetiche mercadoria. 'A Europa se deslocou para ver mercadorias', afirma Taine em 1855"4.

Entende-se com isso que o projeto moderno de desenvolvimento obteve seu sucesso, na medida em que conseguiu colonizar não apenas o ato de produção, mas se enraizou nas mais diversas esferas de sociabilidade. Essa relação entre conteúdo e forma, ou relação de oposição entre capital e trabalho, resulta na dependência da acumulação de capital em relação à expropriação do trabalho, portanto, uma relação que se exprime em uma oposição orgânica, inerente a esta forma de produção. Daí, a dominação não se encontrar, apenas, na relação de produção estabelecida entre "as duas espécies bem diferentes de possuidores de mercadorias" ${ }^{5}$, mas ela invade a vida humana e a condiciona em seus aspectos sociais, políticos e culturais.

A homologação do novo modo de viver condiz com a expansão da massificação e da padronização, que se estende a todas as atmosferas da vida humana. A padronização de um modo de viver, baseado no estranhamento atesta uma aparente autonomia da mercadoria em relação ao seu produtor e impulsiona o caráter fetichista dessa forma de produção ${ }^{6}$.

${ }^{4}$ BENJAMIN, W. Passagens. Belo Horizonte: Editora UFMG; São Paulo: Imprensa Oficial do Estado de São Paulo, 2006, p. 43.

${ }^{5}$ Ao especificar duas espécies bem diferentes de possuidores de mercadoria, Marx destaca que a primeira classe, a capitalista, caracteriza-se por deter a propriedade privada, os meios de produção e o dinheiro; já a segunda classe, os proletários, caracterizam-se por deter, exclusivamente, a sua força de trabalho, sendo este seu único meio de sobrevivência, quando vendida no mercado. MARX, K. O Capital: crítica da economia política, volume I. Trad. Reginaldo Sant'Anna, $2^{\text {a }}$ Ed. Rio de Janeiro: Editora Civilização Brasileira, 1971, p. 829.

${ }^{6}$ Sobre isso, Marx argumenta que: "A forma do valor, a qual tem no dinheiro sua figura acabada, é muito vazia e simples. Apesar disso, tem o espírito humano, há mais de dois mil anos, tentado em vão devassá-la, embora conseguisse analisar, pelo menos com aproximação, formas muito mais complexas e ricas de conteúdo. Por que? Porque é mais fácil estudar o organismo, como um todo, do que suas células. Além disso, na análise das formas economicas, não se pode utilizar nem microscópio nem reagentes químicos. A capacidade de abstração substitui esses meios. A célula economica da sociedade burguesa é a forma mercadoria, que reveste o produto do trabalho, ou a 
A forma padronizada de se viver permuta a necessidade de constituição de uma individualidade autônoma e, em consequência, confere aos homens o status de homo economicus com dois predicados básicos: o consumo e a produção. A característica do funcionamento dos "códigos da vida"7 é atribuída à ação repetitiva, que garante a conservação da vida como mero instrumento do organismo sistêmico.

A consciência é obscurecida em um processo produtivo em que a mercadoria aparece com feições humanas. Atividade vital ao homem, o trabalho, uma vez marcado pelo estranhamento, próprio da forma capitalista de produção, passa a determinar em geral, não apenas, o estranhamento no âmbito da vida econômica, mas também da vida social. A atividade pessoal na sociedade burguesa aparece como atividade para o outro, a apropriação como estranhamento e o estranhamento como apropriação, o trabalho alienado e a vida estranhada, como os homens estranhos a si mesmos.

O processo de produção e reprodução que envolve as categorias fundamentais da realidade social apresenta-se como totalidade concreta, um complexo dinâmico em que seu caráter social encontra-se intimamente ligado ao metabolismo de produção e reprodução do capital ${ }^{8}$. Assim, a vida cotidiana

forma de valor assumida pela mercadoria. Sua análise parece, ao profano, pura maquinação de minuciosidades. Trata-se, realmente, de minuciosidades, mas análogas àquelas da anatomia microscópica." MARX, K. O capital: crítica da economia política, p. 4.

7 Ver aqui BARCELLONA, P. O egoísmo maduro e a insensatez do capital. Trad. Sebastião José Roque. São Paulo: Ícone, 1995.

8 Conforme Missac: "A divisão ou a discordância testemunhas pelo comportamento de Benjamin são provavelmente apenas um aspecto de um problema mais geral, isto é, as condições que determinam a produção de uma obra. Esse problema se coloca paralelamente sobre dois planos, o individual e o coletivo: a criação de um artista e a constituição de um fenômeno cultural. Nos dois casos a obra, seja ela aparentemente a mais autônoma ou a mais claramente destacada do contexto em que se insere, mantêm o traço de suas origens, que devemos apenas descobrir e interpretar. Nas análises conduzidas dessa forma, a biografia e a história 'factual' foram sendo cada vez mais substituídas pelo exame da personalidade do artista (em função frequentemente da 'psicologia das profundezas') e do panorama econômico e social respectivamente. Mas nem por isso elas foram totalmente negligenciadas. Em sua época, Benjamin, na dupla qualidade de crítico literário e de marxista, não deixou de se interrogar sobre esse ponto, de se perguntar como preencher ou transpor o hiato que separa a obra de seu autor ou de sua época. Se ele não forneceu uma análise exaustiva e rigorosa do processo em causa, ao menos buscou e conseguiu designá-lo, como por uma espécie de fidelidade a sua teoria do nome. De um modo que podemos julgar revelador, o vocábulo que Benjamin escolheu então para sintetizar a passagem da infra para a superestrutura, do meio econômico-social para o cultural, se aplica geralmente ao esforço mais pessoal do criador: Ausdruck (a expressão). Entre a economia e a cultura, como ele aponta no Passagenwerk, mais do que (uma relação) de causalidade, trata-se de uma 'relação de expressão [Ausdruckzusammenhang] [...]. A economia se expressa na cultura'. O mecanismo não é desmontado, mas alguma coisa é dada, uma palavra-chave, uma senha, uma metáfora, cujas aplicações nos cabe identificar". MISSAC, P. Passagem de Walter Benjamin. São Paulo: Editora lluminuras, 1998. p. 60. 
enquanto espaço onde se estabelece o começo e o fim de toda ação humana, onde os indivíduos se realizam enquanto tal é, de certo, condicionado pela aparência, às formas fenomênicas.

Assim, ao investigar as formas de reprodução da vida social, Benjamin se depara com um objeto imprescindível à sua reflexão: a mercadoria. Esta é fundamental para entender a constituição mesma do fazer social, uma vez que ela passa a apresentar-se como mediadora da experiência entre o "eu" e o mundo exterior. Além disso, a mercadoria passa a ocupar a totalidade das relações interpessoais, tornando-se assim uma espécie de universal totalizante nas experiências humanas ${ }^{9}$.

Nesse contexto, Benjamin investiga os fenômenos decorrentes dessa nova mediação na "cidade do luxo e da moda", tendo em vista se tratar de um novo universo em que o fazer humano está imerso. Daí a reflexão benjaminiana sobre as Exposições universais se centrar em torno do seu caráter universalizante do mundo mercadorias. Desta feita, as Exposições universais passam a exercer um duplo aspecto: i) atestam o culto à mercadoria, universalizando o desejo de ter, o consumo desmedido e pautando o fazer humano em torno do objeto a ser consumido, e; ii) contribui de forma incisiva no plano ideológico, na medida em que tem por função ser um instrumento de difusão de uma concepção de mundo, com objetivo de divertir a classe trabalhadora, na tentativa de reduzir seu horizonte às ilusões do consumo e do progresso. Em sua crítica às Exposições universais, Benjamin anuncia tais fenômenos e lança críticas contundentes aos saint-simonianos. Benjamin, ao tratar se referir sobre as exposições argumenta que:

\begin{abstract}
Ela nasce do desejo de "divertir as classes trabalhadoras, tornando-se para elas uma festa de emancipação". O operariado situa-se em primeiro plano como clientela. Ainda não se constituíra o quadro da indústria de entretenimento. Esse quadro é formado pela festa popular. A exposição universal é inaugurada pelo discurso de Chapal sobre a indústria. - Os saint-simonianos previram o desenvolvimento da economia mundial, mas não a luta de classes. Sua participação nos empreendimentos industriais e comerciais em meados do século contrasta com sua impotência nas questões relativas ao proletariado ${ }^{10}$.
\end{abstract}

9 De acordo com Bolle: "Com a evocação da loja de departamentos La Ville de Paris, a cidade inteira é transformada alegoricamente numa grande loja. O deciframento dessa paisagem do reclame, da moda e das exposições se dá através da teoria marxista do fetiche da mercadoria, reformulada por Benjamin em termos de uma 'empatia para com a alma da mercadoria'". BOLLE, W. A metrópole como medium-de-reflexão. In:Leituras de Walter Benjamin. Org: Márcio Seligmann. São Paulo: FAPESP: Annablume, 2007, p. 107.

${ }^{10}$ BENJAMIN, Walter. Passagens, p. 44. 
Sem hesitar, Benjamin contesta de uma só vez a função das Exposições universais, além disso, questiona todo aquele antigo ideal de progresso e industrialização, algo tão presente neste período.

As Exposições universais, enquanto universo das mercadorias, se configuram agora como os locais de lazer coletivos. Até mesmo o ócio passa a se vincular a este universo. A modernidade inaugura a instituição e a determinação até mesmo de o lazer, por meio destes locais. O culto ao sistema parece estar sempre disposto à renovação. O tempo reduz-se ao eterno presente, pois não há mais lugar para a experiência, visto que o agir é repetitivo e o espaço reduz-se ao uniforme, o corpo não é mais tido como potência vital, mas reduz-se a um objeto segmentado ${ }^{11}$. Trabalho e lazer não fogem mais a regra geral, que condiciona todas as camadas sociais, ao culto da produção e reprodução do capital, tanto em aspectos práticos quanto naqueles ideológicos.

Com isso, as Exposições universais surgem como uma espécie de suspensão daquele estágio de conflito entre as classes. Revela-se ainda o objetivo de transmissão de determinados valores éticos, morais e até mesmo estéticos ${ }^{12}$. A

${ }^{11}$ Conforme Adorno, em um artigo intitulado Adorno, su Walter Benjamin: "La seconda fase del progetto dell'opera sui passaggi è documentata nel memorandum scritto nel 1935, Paris, die Hauptstadt des XIX. Jahrhunderts [Parigi. La capitale del XIX secolo]. Esso pone in puntuale rapporto configurazioni chiave dell'epoca con categorie del mondo figurativo. Vi si doveva trattare di Fourier e Daguerre, di Grandville e Luigi Filippo, di Baudelaire e Haussmann, ma il lavoro si appuntò su temi quali la moda e le «novità», le esposizioni e le costruzioni in ghisa, il collezionista, il flâneur, la prostituzione. Quanto estremamente ampio e stimolante sia l'arco interpretativo, l'attesta per esempio questo brano su Grandville: «Le esposizioni mondiali edificano l'universo delle merci. Le fantasie di Grandville trasferiscono il carattere di merce all'universo. Lo modernizzano. L'anello di Saturno diventa un balcone in ghisa su cui gli abitanti di Saturno prendono aria la sera... La moda prescrive il rituale secondo cui va adorato il feticcio della merce; Grandville estende i diritti della moda agli oggetti dell'uso quotidiano e al cosmo intero. Seguendola nei suoi estremi, egli scopre la sua natura. Essa è in conflitto con l'organico." In: T. W. Adorno, em "Prism", Einaudi, Turim 1972, p. 233-247. Tradução livre: "A segunda fase do projeto da obra, sobre as passagens, é documentado em um memorando escrito em 1935, Paris, a capital do século XIX. Ele põe em pontual relação configurações chaves da época com categorias do mundo figurativo. Ao tratar sobre Fourier e Daguerre, Grandville e Luigi Filippo, Baudelaire e Haussmann, mas o trabalho se caracterizou sobre temas como moda e a "novidade", as exposições e as construções de ferro fundido, o colecionador, o flâneur, a prostituição. Extremamente amplo e desafiador foi o arco interpretativo, atestado, por exemplo, neste trecho de Grandville: "As exposições mundiais edificam o universo das mercadorias. A fantasia de Grandville transferiu o caráter de mercadoria ao universo. $O$ modernizado. $\mathrm{O}$ anel de Saturno torna-se uma varanda de ferro fundido em que os habitantes de Saturno sentem o ar da noite... A moda prescreve o ritual conforme a adoração ao fetichismo da mercadoria; Grandville estende os direitos dos objetos de moda do uso cotidiano e todo o cosmo. Após isso, em seus extremos, ele descobre sua natureza. Ele está em conflito com o orgânico.". In: T. W. Adorno, em "Prism", Einaudi, Turim 1972, p. 233-247. Extraído de: www.filosofico.net/Antropologia_file/Antologia/Adorno_17.html

${ }^{12}$ Conforme Barbuy: "É verdade que a Exposição de 1851 nasceu - nisso seguida pelas demais do século XIX - com o caráter primeiro daquilo que chamamos de feira industrial (exibição e comércio 
inauguração destes locais representa, igualmente, a possibilidade de difusão da ilusão de uma coexistência harmoniosa entre as classes, uma vez que a mercadoria passa o objeto de um novo sonho em um mundo marcado pelo fetichismo. Assim, as Exposições passam a cumprir um papel fundamental na padronização do modo de vida.

Assim, as Exposições universais se constituem enquanto locais de "peregrinação ao fetiche mercadoria". Desse modo, as passagens, o lazer, a moda, a propaganda e tantas outras expressões das relações sociais passam a ser orientadas pela mercadoria, ou por assim dizer, passam a ser expressão de um mundo fantasmagórico regido pela mercadoria. Não obstante, o valor de troca adentra o delírio onírico do imaginário coletivo de toda uma sociedade. De acordo com Benjamin:

\begin{abstract}
As exposições universais constroem o universo das mercadorias. As fantasias de Grandvile transferem para o universo o caráter de mercadoria. Elas o modernizam. O anel de Saturno torna-se uma sacada de ferro fundido, na qual à noite os habitantes de Saturno tomam ar fresco. O contraponto literário desta utopia gráfica é representado pelos livros do naturalista Toussenel, seguidor de Fourier. - A moda prescreve o ritual segundo o qual o fetiche mercadoria deseja ser adorado. Ela se encontra em conflito orgânico, unindo o corpo vivo ao mundo inorgânico e fazendo valer no corpo vivo os direitos do cadáver. O fetichismo subjacente a sex appeal do inorgânico é seu nervo vital. O culto da mercadoria coloca-o a seu serviço ${ }^{13}$.
\end{abstract}

Daí, a vida cotidiana, enquanto imediaticidade, espaço onde os indivíduos se realizam como tal, todavia, relegados ao materialismo espontâneo, é de certo o lugar onde a essência das relações sociais e a aparência, as forma fenomênicas fruto das relações sociais de produção se interligam. As formas padronizadas, a homogeneização das ações e das disposições, o definhamento da faculdade criativa, da imaginação, do conceito de realidade, apresentam-se como expressões

de produtos), mas imediatamente as exposições excederam esse objetivo para se configurar como representações do mundo. Naquele período, no entanto, a grande chave que se propunha para o mundo era justamente a industrialização. $E$ foi isso, na verdade, o que mudou: com a descrença na ideologia do progresso, mudou a proposta de mundo, mas não se pode dizer que o que se vendia antes não fosse um mundo ou um modo de vida. Ao contrário. Assim também, em outro momento, Rasmussen explica a Exposição de 1992, organizada em Sevilha: '... quatro pavilhões temáticos, tudo com a apresentação de conceitos abstratos (a visão da história, a concepção do futuro, a capacidade imaginativa do homem) e de produção cultural (arquitetura, design, ciência, tecnologia, artes, espetáculos), respeitando-se os quadros nacionais expressos por pavilhões. O projeto de classificação da exposição universal atesta bem a evolução dos objetos de exposição: passou-se do industrial ao cultural, da exposição de produtos à exposição de conceitos' (Rasmussen, 1992: 37)" BARBUY, H. A exposição universal de 1889. Edições Loyola, São Paulo: 1999. p. 40-41.

${ }^{13}$ BENJAMIN, Walter. Passagens, p. 45. 
do modo de viver burguês, que associado ao caráter fetichista da mercadoria, passam a constituir essa fantasmagoria da cultura capitalista.

Dessa maneira, nas relações sociais de produção próprias da forma capitalista de produção, criam-se não apenas valor de uso, mas também valor de troca $^{14}$, sendo este um produto da vida social, ou seja, da implicação direta da atividade humana, o trabalho social. Todavia o "desenvolvimento da mercadoria não suprime essas contradições, mas cria a forma em que elas podem se mover"15. Entendendo tal reflexão, Benjamin se reporta às Exposições universais enquanto locais privilegiados de exposição do valor de troca das mercadorias, tendo estas a capacidade ilusória e a competencia de ocultar as relações sociais, condicionando as ações em torno da sua obtenção. Conforme Benjamin:

As exposições universais idealizam o valor de troca das mercadorias. Criam um quadro no qual seu valor de uso passa para o segundo plano. Inauguram uma fantasmagoria a que o homem se entrega para divertir-se. A indústria de entretenimento facilita isso elevando-o ao nível da mercadoria. Ele se abandona às suas manipulações ao desfrutar a sua própria alienação e a dos outros. - A entronização da mercadoria e o brilho da distração que a cerca é o tema secreto da arte de Grandville. A isso corresponde a discrepância ente seu elemento utópico e seu elemento cínico. Suas especiosidades na representação de objetos inanimados correspondem àquilo que Marx denomina de "argúcias teológicas" da mercadoria. Estas se manifestam claramente na spécialité - designação de uma mercadoria que surge nesta época na indústria de luxo. Sob o lápis de Grandville, a natureza inteira se transforma em especialidades. Ele as apresenta no mesmo espírito no qual o reclame - também esta palavra surge naquela época - começa a apresentar seus artigos. Ele acaba demente. [...] Por ocasião da exposição universal de 1867, em Paris, Victor Hugo lança um manifesto "Aos povos da Europa". Os interesses deles foram defendidos antes e de modo menos equivoco pelas delegações de trabalhadores franceses, cuja primeira participou da exposição universal de Londres, em 1851, e a segunda, com 750 representantes, da exposição de 1862. Esta última foi importante, pois contribuiu indiretamente para a fundação da Associação Internacional dos Trabalhadores, por Marx. - A fantasmagoria da cultura capitalista alcança seu desdobramento mais brilhante na exposição universal de 1867. O Império está no seu auge de seu poder. Paris afirma-se como capital do luxo e das modas. Offenbach prescreve o ritmo da vida parisiense. A opereta é a irônica utopia de um domínio duradouro do capital ${ }^{16}$

\footnotetext{
${ }^{14}$ Marx ainda esclarece que os "valores de uso são, de modo imediato, meios de subsistencia. Mas, por seu lado, estes meios de existencia são eles próprios produtos da vida social, o resultado de um dispendio de força vital humana, são trabalho materializado. Enquanto materialização do trabalho social, todas as mercadorias são cristalizações da mesma unidade. É o carater determinado desta unidade, isto é, do trabalho, manifestado no valor de troca”. MARX, K. Contribuição à Crítica da Economia Política. Trad. Florestan Fernandes. São Paulo: Expressão Popular, 2007, p. 13.

${ }^{15}$ FAUSTO, R. Dialética marxista, dialética hegeliana: a produção capitalista como produção simples. São Paulo: Paz e terra, 1997, p. 101.

${ }^{16}$ BENJAMIN, Walter. Passagens, p. 44-45.
} 
Por fim, com base no percurso aqui apresentado, consideramos que a crítica benjaminiana compreende não apenas uma mera descrição da forma capitalista de produção, em termos restritos, em um sentido puramente economicista, ao contrário, a intenção de Benjamin é aquela de demonstrar a totalidade orgânica desta forma de produção, abordando não apenas aspectos objetivos da produção e reprodução da forma capitalista de produção, mas ressaltando inclusive a relação entre objetividade e subjetividade, entre forma de produção e sua relação com o universo da cultura. Portanto, compreendemos este escrito benjaminiano, como uma crítica às relações sociais de produção e reprodução de um determinado modo de vida, imerso no contexto de uma forma específica de produção, trata-se assim de um retrato vivo, que apresenta uma reflexão profundamente reveladora sobre a cultura, o fazer social e a mercadoria como reguladora quer das relações interpessoais quer da relação dos indivíduos com o espaço socialmente constituído. 


\section{REFERÊNCIAS}

ADORNO, T. Prism, Einaudi, Turim 1972, p. 233-247. Extraído de: www.filosofico.net/Antropologia_file/Antologia/Adorno_17.html.

BARBUY, H. A exposição universal de 1889. Edições Loyola, São Paulo: 1999.

BARCELLONA, P. O egoísmo maduro e a insensatez do capital. Trad. Sebastião José Roque. São Paulo: Ícone, 1995.

BENJAMIN, W; SCHOLEM, G. Correspondência. Trad. Neusa Soliz. São Paulo: Perspectiva, 1993.

Passagens. Belo Horizonte: Editora UFMG; São Paulo: Imprensa Oficial do Estado de São Paulo, 2006.

BOLLE, W. A metropole como medium-de-reflexão. In: Leituras de Walter Benjamin. Org: Márcio Seligmann. São Paulo: FAPESP: Annablume, 2007

FAUSTO, R. Dialética marxista, dialética hegeliana: a produção capitalista como produção simples. São Paulo: Paz e terra, 1997.

LOWY, M. A filosofia da história de Walter Benjamin, disponível em: http://www.scielo.br/scielo.php?pid=S0103-40142002000200013\&script=sci_arttext

MARX, K. O Capital: crítica da economia política. Trad. Reginaldo Sant'Anna, $2^{\mathrm{a}}$ Ed. Rio de Janeiro: Editora Civilização Brasileira, 1987.

MARX, K. Contribuição à Crítica da Economia Política. Trad. Florestan Fernandes. São Paulo: Expressão Popular, 2007.

MISSAC, P. Passagem de Walter Benjamin. São Paulo: Editora lluminuras, 1998. 


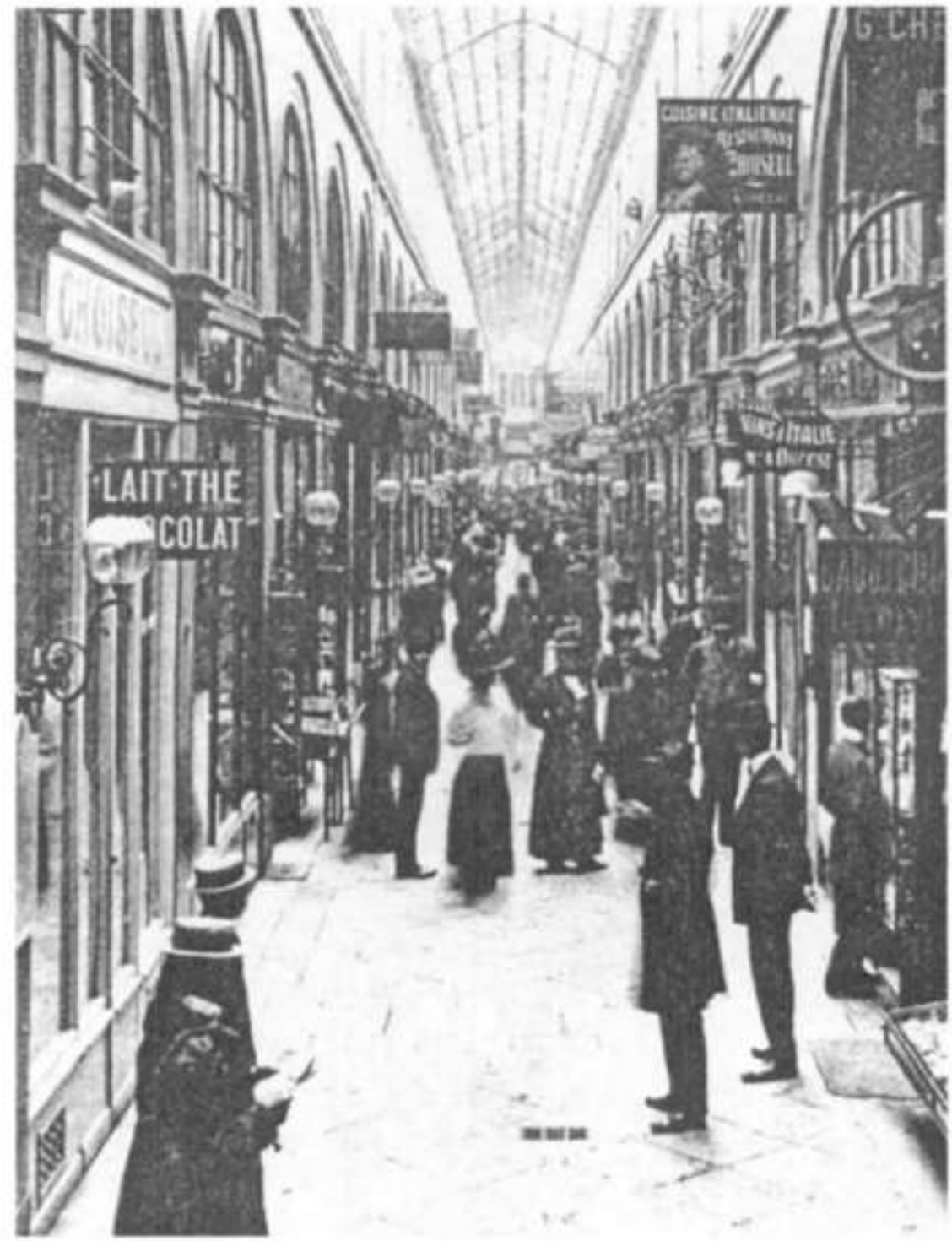

"O sonho - cis a terra onde se fazem as descobertas que testemunham a história primeva do século XIX"

Walter Benjamin, "Arquivo C", Passagens.

Passage Choiseul, 1908 , fotógrafo desconhecido.

"O grande instinto americano, importado para a capital por um préfet do segundo Império, que contribui para recortar regularmente o plano de Paris vai, dentro em breve, tornar impossivel a manutençào desses aquários humanos que jả morreram para sua vida primitiva e que merecem, entretanto, ser olhados como os receptadores de diversos mitos modernos, pois apenas hoje, quando a picareta os ameaça, é que eles se transformaram efetivamente nos santuários dum culto do efẻmero, na paisagem fantasmática dos prazeres e das profissōes malditas, incompreensiveis hoje, e que o amanhả não conhecerả jamais".

Louis Aragon, "A Passagem da Ópera", O camponếs de Paris.

Figura 01: Passage Choiseul, extraída de A constelação do sonho em Walter Benjamin. 